\title{
Synthesis of Poly(Conjugated Ester)s by Ring-Opening Polymerization of Cyclic Hemiacetal Ester Bearing Acryl Skeleton
}

\author{
Yasuhiro Kohsaka, ${ }^{* 1,2}$ Mai Yamashita, ${ }^{2}$ Yosuke Matsuhashi $^{2}$ and Shuji Yamashita ${ }^{2}$ \\ ${ }^{1}$ Research Initiative for Supra-Materials (RISM), Shinshu University \\ ${ }^{2}$ Faculty of Textile Science and Technology, Shinshu University, 3-15-1 Tokida, Ueda, Nagano 386- \\ 8567, Japan \\ * Tel: +81-268-21-5488, E-mail: kohsaka@shinshu-u.ac.jp
}

Keyword: ring-opening polymerization / cyclic hemiacetal ester / $\alpha$-exomethylene lactone / poly(conjugated ester) / conjugate substitution / chemoselective main chain scission

\begin{abstract}
Ring-opening polymerization (ROP) of 2,6-dimethyl-5-methylene-1,3-dioxan-4-one (DMDO), a cyclic hemiacetal ester containing an acrylate skeleton, was investigated. Although the ROPs catalyzed by tin(II) 2-ethylhexanoate [Sn(Oct) 2 and 1,5,7-triazabicyclo[4.4.0]dec-5-ene (TBD) did not yield polymeric products, diphenyl phosphate (DPP) functioned a catalyst for the ROP through acyl scission accompanying with the elimination of acetaldehyde at $50{ }^{\circ} \mathrm{C}$ and $80{ }^{\circ} \mathrm{C}$. The resulting polymer was a poly(conjugated ester) that had similar structure to the polymer of $\alpha$-methylene- $\beta$ butyrolactone $\left(\mathrm{M}_{\beta} \mathrm{BL}\right)$, an $\alpha$-exomethylene lactone with four-membered ring. Copolymerizations of $\varepsilon$-caprolactone and $\delta$-valerolactone were also performed to yield the corresponding polyesters. The chemoselective main chain scission of the copolymers at the conjugated ester units were achieved by conjugate substitution reaction with benzyl mercaptan. Although the ROP of DMDO left a problem in the control of molecular weight, DMDO exhibited a potential as an easier accessible monomer alternative to $\mathrm{M}_{\beta} \mathrm{BL}$ for the preparation of bio- and chemo-degradable polyesters.
\end{abstract}

\section{Introduction}

Recently, poly(conjugated ester) (PCE), a polyester carrying acrylate skeletons in the backbone, has gained much attention for a biodegradable functional polymer in next generations. In addition to the biodegradability as an aliphatic polyester, the acrylate skeleton allows thermal-/photo-curing, crosslinking, and chemical modification[1-5]. For example, Klok et al. have reported the quantitative functionalization of PCEs by thiol-ene click chemistry[2]. As Klok’s PCEs contain hydroxy groups as pendants, they have also succeeded the orthogonal functionalization with isocyanates.

There are two strategies to synthesize PCEs: Step-growth polymerization and ring-opening 
polymerization (ROP). Historically, itaconic acid, a natural product that have two carboxy groups and an acryl skeleton, has been used as a monomer for PCEs[6]. For example, the direct polycondensation with itaconic acid and diols afforded PCEs[7,8]. However, the resulting polymers were unstable and usually treated in the presence of polymerization inhibitors[7]. Recently, Baylis-Hillman reaction have been reported as an efficient method to prepare PCEs or their monomers[2,3]. Klok and coworkers synthesized PCEs by the polycondensation of diacrylate and dialdehyde[2], whereas Joy et al. prepared a diol monomer by Baylis-Hillman reaction of 2-hydroxyethyl acrylate the subsequent polyaddition with diisocyanate yielded PCEs[3]. More recently, we have reported that conjugated substitution reaction of bis[ $\alpha$-(halomethyl)acrylate] is effective to access PCEs[9]. The polymerization could be conducted with various nucleophilic monomers such as dicarboxylic acids, bisphenols and dithiols to afford PCEs with high molecular weight $\left(M_{\mathrm{n}} \sim 6 \times 10^{4}\right)$ even at room temperature.

ROPs of $\alpha$-exomethylene lactones, i.e. cyclic acrylates, are also promising route to PCEs[1,1015]. However, the reactivity of $\alpha$-exomethylene lactone is not high, and copolymerization with common lactones have been primarily investigated[12]. In 2016, Y.-X. Chen et al. developed a new catalytic system for the ROP of $\alpha$-methylene- $\gamma$-butyrolactone $\left(\mathrm{M}_{\gamma} \mathrm{BL}\right)$. This report implies that special catalyst design is required to achieve ROP of $\alpha$-exomethylene lactone[13]. In contrast, X-B. Lu et al. reported that the ROP of $\alpha$-methylene- $\beta$-butyrolactone $\left(\mathrm{M}_{\beta} \mathrm{BL}\right)$, an $\alpha$-exomethylene lactone with four-membered ring, could be employed with a common salen-aluminum complex catalyst (Scheme 1) $[14,15]$. The polymerization is living and the synthesis of a block copolymer with controlled molecular weight was achieved[15]. More importantly, the resulting polymer has the simplest backbone as a PCE, that is, acryl skeletons are connected each other through single carbon atom. In addition to the curability and post-polymerization reactivity by the acrylate skeletons, the aforementioned unique structure would lead to the chemical degradability. The literature described the main chain scission of the PCE by a treatment with amines, although the authors did not ditect the reaction mechanism[15]. Our latest research revealed similar main chain scission of PCE through conjugate substitution reaction, where the oxycarbonyl group at the allylic position functioned as an excellent leaving group to release carboxylate anion[9]. Therefore, Lu's PCE would be decomposed in a similar mechanism. Such chemical degradation is expected to support the decomposition of biodegradable polymer under natural environments, as biodegradation often need long time-scale[16]. Hence, a PCE from $\mathrm{M}_{\beta} \mathrm{BL}$ is a promising polymer material with curability, post-polymerization reactivity and bio-/chemical-degradability. However, the preparation of $\mathrm{M}_{\beta} \mathrm{BL}$ needs long step reactions [14] and this remains as a significant issue. Then, we have expected 2,6-dimethyl-5- 
methylene-1,3-dioxan-4-one (DMDO), which could be prepared from acryloyl chloride in two steps[17], as an alternative monomer (Scheme 1).

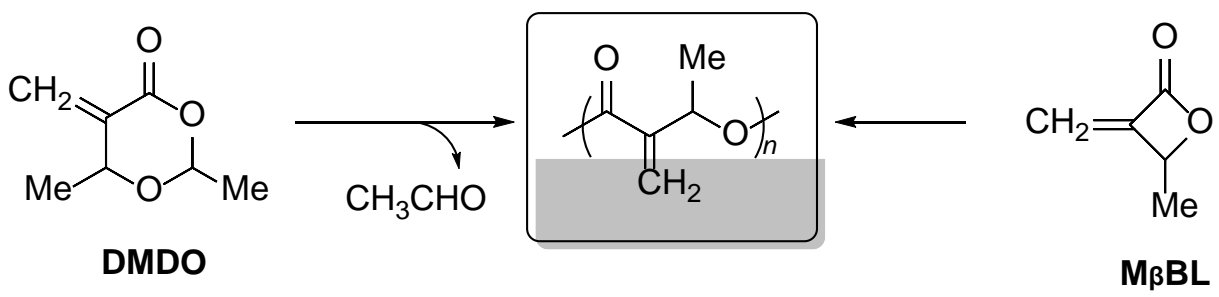

Scheme 1. ROPs of DMDO and $\mathrm{M}_{\beta} B L$.

Since we have investigated the polymerization chemistry of $\alpha$-functionalized acrylate[18,19], the anionic polymerization of DMDO have been investigated [17] in order to understand the isotacticspecific polymerization behavior of $\alpha$-(alkoxymethyl)acrylate[20-22]. DMDO also have an aspect of a cyclic hemiacetal ester. It is known that cyclic hemiacetal esters can undergo two different ROP modes[23, 24]; the direct ROP yielded a poly(hemiacetal ester), whereas the ROP with the elimination of aldehyde afforded a polyester [23,25,26]. Their selectivity is dependent on the catalyst and its concentration[23,24]. For example, diphenyl phosphate (DPP) generally catalyzed the direct ROP[24]. We had envisioned as the ROP of DMDO catalyzed by DPP would afford the corresponding poly(hemiacetal ester), but the resulted polymer was the polyester formed by ROP accompanying the elimination of aldehyde. Herein, we describe the ROP of DMDO to synthesize a PCE that has similar structure to the ROP product of $\mathrm{M}_{\beta} \mathrm{BL}$.

\section{Experiments}

\section{Instruments}

${ }^{1} \mathrm{H}$ and ${ }^{13} \mathrm{C}$ NMR spectra were recorded in $\mathrm{CDCl}_{3}$ (Across Organics) on AVANCE 400 (Bruker) and AVANCE NEO (Bruker) spectrometers. Chemical shifts in ${ }^{1} \mathrm{H}$ and ${ }^{13} \mathrm{C}$ NMR spectra were referred to the signal of tetramethylsilane (TMS) and solvent $\left(\mathrm{CDCl}_{3}\right)$, respectively. Molecular weight and its distributions were determined at $40{ }^{\circ} \mathrm{C}$ by sizeexclusion chromatography (SEC) on an EXTREMA chromatograph (JASCO) equipped with two SEC columns [PL-gel, Mixed C (300 mm _7.5 mm), Polymer Laboratories], using tetrahydrofuran (THF, Wako Pure Chemical Industries, for HPLC grade) as an eluent (flow 
rate $=0.8 \mathrm{~mL} \min ^{-1}$ ), and calibrated against standard polystyrene (PS) samples (TSK-gel oligomer kit, Tosoh, $M_{\mathrm{n}}$ : $1.03 \times 10^{6}$, $3.89 \times 10^{5}, 1.82 \times 10^{5}, 3.68 \times 10^{4}, 1.36 \times 10^{4}, 5.32 \times 10^{3}$, $\left.3.03 \times 10^{3}, 8.73 \times 10^{2}\right)$ and detected with UV (UV-4070, JASCO) and RI (RI-4030, JASCO) detectors. IR spectra were recorded on a Cary 630 FTIR spectrometer equipped with a transmission attachment. Gas chromatography was employed on a GC-2014 (Shimadzu) equipped with a capillary column (SH Rtx-5), using helium as a movable phase and make up gas (line rate $30 \mathrm{~cm} \mathrm{~s}^{-1}$ ) and detected with a flame ionization detector (FID-2014).

\section{Materials}

Acryloyl chloride was provided by Iharanikkei Chemical Industry Co., Ltd. Toluene (Aldrich, anhydrous grade) was dehydrated with red colored adduct of butyllithium ( $n$-BuLi) and 1,1diphenylethene, and distilled under high vacuum just before use. 4-(1,1,3,3Tetramethylbutyl)phenol, tin(II) 2-ethylhexanoate, $\delta$-valerolactone (VL) and 1,5,7triazabicyclo[4.4.0]dec-5-ene (TBD) were purchased from Tokyo Chemical Industry Co., Ltd. Amberlyst A21 and diphenyl phosphate (DPP) were purchased from Sigma-Aldrich (Merck). Other chemicals were purchased from Fujifilm Wako Pure Chemical Industry Co. DMDO was prepared according to our previous report[17]. DMDO, VL and $\varepsilon$-caprolactone (CL) were dried over $\mathrm{CaH}_{2}$ under dried $\mathrm{N}_{2}$ atmosphere and distilled just before use.

\section{Synthesis of BDDMO}

Benzyl mercaptan (16.4 g, $132 \mathrm{mmol})$ and $\mathrm{Bu}_{3} \mathrm{P}$ (5.71 g, $28.2 \mathrm{mmol}$ ) was added to a solution of DMDO (13.4 g, $93.9 \mathrm{mmol}$ ) in $\mathrm{CH}_{3} \mathrm{CN}$ (50 mL). The reaction mixture was stirred for $12 \mathrm{~h}$ and concentrated. BDDMO was purified on silica gel column chromatography [eluent: EtOAc/hexane $\left.=5 / 1(\mathrm{v} / \mathrm{v}), R_{\mathrm{f}}=0.34\right]$ as colorless oil $(6.21 \mathrm{~g}, 24.9 \%) .{ }^{1} \mathrm{H} \mathrm{NMR}(400 \mathrm{MHz}$, $\mathrm{CDCl}_{3}, 26^{\circ} \mathrm{C}$ ) $\delta / \mathrm{ppm}$ 7.35-7.22 (m, 5H), 5.50 (q, $\left.J=5.1 \mathrm{~Hz}, 1 \mathrm{H}\right), 4.06-3.99$ (m, 1H), 3.80-3.73 (m, 2H), 3.12 (dd, $\left.J_{1}=15.6 \mathrm{~Hz}, J_{2}=5.1 \mathrm{~Hz}, 1 \mathrm{H}\right), 2.64-2.59$ (m, 2H), 1.48 (d, $\left.J=5.1 \mathrm{~Hz}, 3 \mathrm{H}\right), 1.26$ (d, $J$ $=6.1 \mathrm{~Hz}, 3 \mathrm{H})$.

\section{Polymerization}

A typical procedure (Table 1, Entry 6): A toluene solution of benzyl alcohol (1.07 M, 0.187 mL, 0.200 mmol), DMDO (0.654 mL, $5.00 \mathrm{mmol})$ and CL (0.528 mL, $5.0 \mathrm{mmol}$ ) were added with hypodermic syringes to a round bottom flask filled in dried $\mathrm{N}_{2}$ gas passed through molecular sieves $4 \mathrm{~A}$ cooled at $-78^{\circ} \mathrm{C}$. The reaction mixture was heated at $80^{\circ} \mathrm{C}$, and a solution of DPP $(0.498 \mathrm{M}, 0.402 \mathrm{mmol})$ was added. The reaction mixture was sampled at the determined time. After $24 \mathrm{~h}$, the reaction mixture was diluted with toluene $(2 \mathrm{~mL})$, and the solution was poured into hexane $(40 \mathrm{~mL})$ cooled at $-70{ }^{\circ} \mathrm{C}$, and 
the precipitate was collected by decantation. The precipitate was dried in vacuo at $40{ }^{\circ} \mathrm{C}$ for $5 \mathrm{~h}$.

\section{Chemoselective degradation of the copolymer}

$\mathrm{Et}_{3} \mathrm{~N}$ (46 mg, $0.39 \mathrm{mmol}$ ) and benzyl mercaptan (44 mg, $0.36 \mathrm{mmol}$ ) were added to a solution of the copolymer of DMDO and CL obtained in Entry 6 (0.11 g, $0.30 \mathrm{mmol}$ for conjugated ester units) in $\mathrm{CHCl}_{3}(0.9 \mathrm{~mL})$. The reaction mixture was stirred for $24 \mathrm{~h}$ and brine $(1 \mathrm{~mL})$ and $1 \mathrm{M} \mathrm{HCl}$ aq $(1 \mathrm{~mL})$ were added. The mixture was washed, and the organic layer was concentrated and dried in vacuo. ${ }^{1} \mathrm{H}$ NMR spectrum and SEC of the residue were measured.

\section{Results and Discussion}

\section{Homopolymerization of DMDO}

DMDO was prepared according to our previous report (cis/trans $=91 / 9)$. In our initial attempt, DMDO was polymerized with a catalyst of tin(II) 2-ethylhexanoate [Sn(Oct) $)_{2}$ and benzyl alcohol as an initiator at $80^{\circ} \mathrm{C}$ in bulk, as this was the common procedure for ROP of lactones (Table 1, Entry 1)[27]. However, the product was insoluble in common organic solvent such as $\mathrm{CHCl}_{3}$ and tetrahydrofuran (THF), probably due to the thermal polymerization at the acryl skeleton. Therefore, the polymerization should be conducted at lower temperature. Recently, organic molecular catalyst such as 1,5,7-triazabicyclo[4.4.0]dec-5-ene (TBD)[28,29] and DPP[30] have been developed as an efficient catalyst for ROP of lactones even at room temperature. Then, ROPs of DMDO with these catalysts were investigated (Entries 2 and 3), although no polymeric product was obtained. 
Table 1. (Co)polymerizations of DMDO and other lactones initiated by $\mathrm{BnOH}$.

\begin{tabular}{|c|c|c|c|c|c|c|c|c|c|c|c|c|c|}
\hline \multirow[b]{3}{*}{ Entry $^{\mathrm{a}}$} & \multirow[b]{3}{*}{$\mathrm{M}_{2}^{\mathrm{b}}$} & \multirow[b]{3}{*}{ Catalyst } & \multirow{3}{*}{$\begin{array}{c}\text { Temp. } \\
{\left[{ }^{\circ} \mathrm{C}\right]}\end{array}$} & \multirow{3}{*}{$\begin{array}{c}\text { Time } \\
{[\mathrm{h}]} \\
\end{array}$} & \multicolumn{4}{|c|}{ Conversion $^{\mathrm{c}}(\%)$} & \multirow{3}{*}{$\begin{array}{c}\text { Yield } \\
\text { [\%] }\end{array}$} & \multirow[b]{3}{*}{$M_{\mathrm{n}}^{\mathrm{d}}$} & \multirow[b]{3}{*}{$\bigoplus^{\mathrm{d}}$} & \multicolumn{2}{|c|}{ Comp. $^{\mathrm{c}}(\%)$} \\
\hline & & & & & & $\mathrm{M}_{1}$ & & $\mathrm{M}_{2}$ & & & & & \\
\hline & & & & & total & cis & trans & & & & & $\mathrm{M}_{1}$ & $\mathrm{M}_{2}$ \\
\hline 1 & - & $\mathrm{Sn}(\mathrm{Oct})_{2}$ & 80 & 16 & \multicolumn{9}{|c|}{ Gelation } \\
\hline 2 & - & TBD & 25 & 8 & \multicolumn{9}{|c|}{ No polymer } \\
\hline 3 & - & $\mathrm{DPP}$ & 25 & 24 & \multicolumn{9}{|c|}{ No polymer } \\
\hline 4 & - & DPP & 50 & 18 & 27 & & & & 5 & 2300 & 1.32 & 100 & \\
\hline 5 & - & DPP & 80 & 18 & 80 & & & & 41 & 1600 & 1.99 & 100 & \\
\hline $6^{e}$ & CL & DPP & 50 & 40 & 41 & 3 & 44 & 96 & $-f^{f}$ & 4000 & 1.52 & 26 & 74 \\
\hline 7 & CL & DPP & 80 & 24 & 70 & 50 & 72 & $>99$ & $-f^{f}$ & 3200 & 2.32 & 37 & 63 \\
\hline 8 & VL & $\mathrm{DPP}$ & 50 & 18 & 43 & & & 98 & 26 & 2200 & 1.30 & 22 & 78 \\
\hline 9 & VL & DPP & 80 & 18 & 95 & & & 96 & 48 & 2100 & 1.44 & 43 & 57 \\
\hline
\end{tabular}

${ }^{\mathrm{a}}\left(\left[\mathrm{M}_{1}\right]_{0}+\left[\mathrm{M}_{2}\right]_{0}\right) /[\mathrm{BnOH}]_{0} /[\text { catalyst }]_{0}=50 / 1 / 1$.

$\mathrm{b}\left[\mathrm{M}_{1}\right] /\left[\mathrm{M}_{2}\right]=1$.

${ }^{\mathrm{c}}$ Determined by ${ }^{1} \mathrm{H}$ NMR spectrometry (400 MHz, $\mathrm{CDCl}_{3}, 25^{\circ} \mathrm{C}$ ).

${ }^{\mathrm{d}}$ Determined by SEC (THF, $40^{\circ} \mathrm{C}$, polystyrene standards).

e $\left(\left[\mathrm{M}_{1}\right]_{0}+\left[\mathrm{M}_{2}\right]_{0}\right) /[\mathrm{BnOH}]_{0} /[\text { catalyst }]_{0}=100 / 1 / 1$.

${ }^{\mathrm{f}}$ Isolated yield could not be determined as the reaction mixture were sampled to monitor the ROPs for Figure 2. 


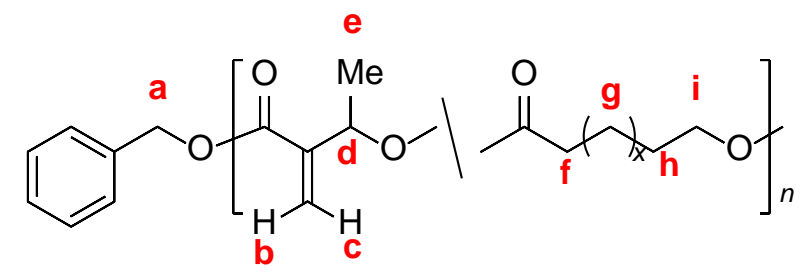

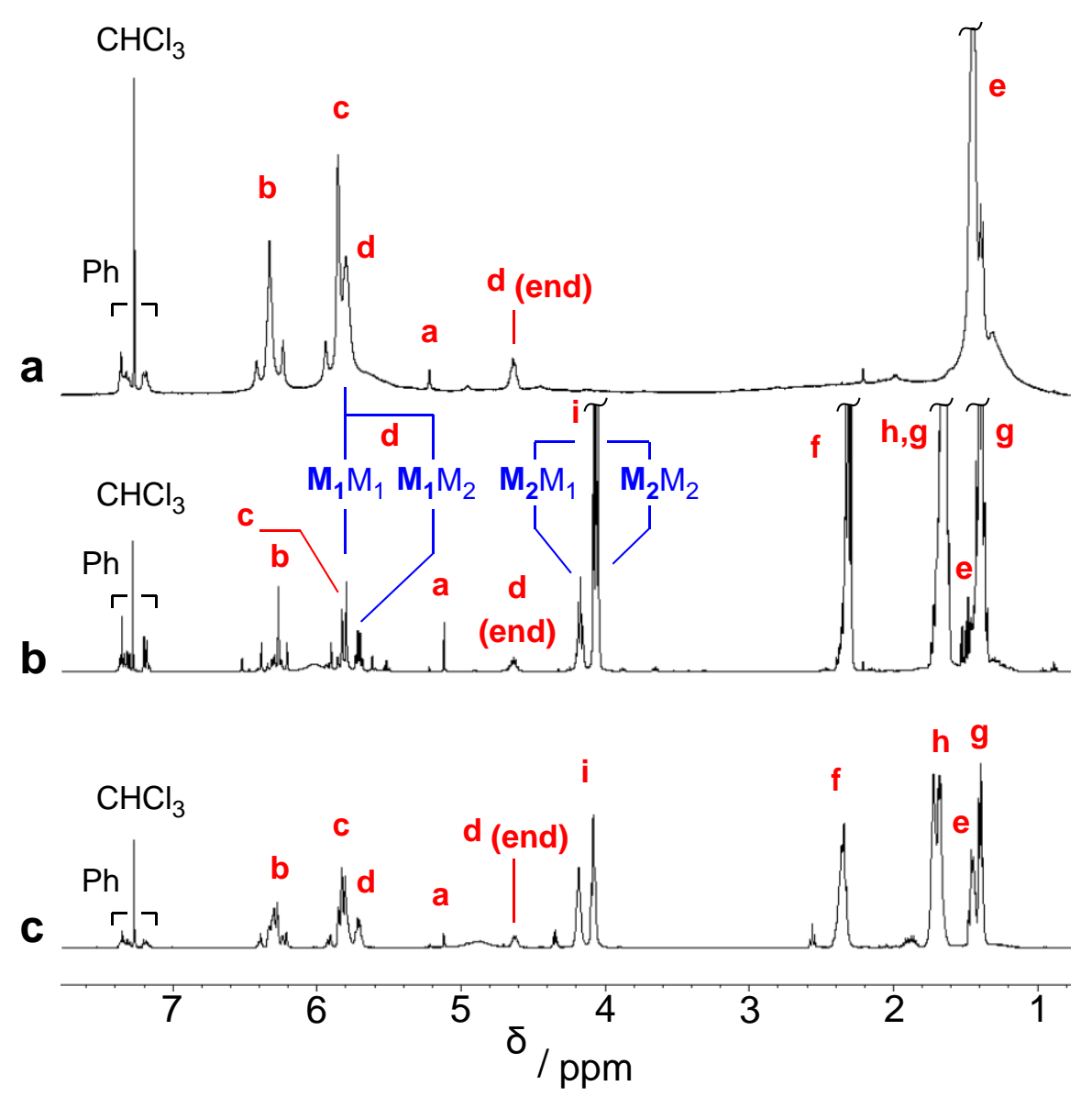

Figure 1. ${ }^{1} \mathrm{H}$ NMR spectra of the obtained polymers in Entries 5 (a), 6 (b) and 9 (c) (400 MHz, $\left.\mathrm{CDCl}_{3}, 25^{\circ} \mathrm{C}\right)$.

After our above experiments, Hillmyer el al. reported the ROP of cyclic hemiacetal ester catalyzed with DPP that proceeded with the cleavage of acetal bond [24]. It seems strange that no polymerization occurred for DMDO in a similar condition. DMDO is a conjugated ester and the structural features would be attributed to the different reactivity than common cyclic hemiacetal esters. This point is discussed later with the results of ROP after thiol-ene functionalization of DMDO. The ROP was also conducted at $50{ }^{\circ} \mathrm{C}$ and $80^{\circ} \mathrm{C}$ (Entries 4 and 5). In both case, polymeric products were obtained, although the molecular weight were lower than expected. The ${ }^{1} \mathrm{H}$ NMR spectrum of the obtained product in Entry 5 is shown in Figure 1a. All signals are similar to that of poly $\left(\mathrm{M}_{\beta} B L\right)[14]$, although the vinylidene signals around 6.3 and $5.8 \mathrm{ppm}$ are split in different intensities due to the 
differences in stereoregularity. That is, our polymer is atactic, whereas the reported poly $\left(\mathrm{M}_{\beta} \mathrm{BL}\right)$ prepared in coordination polymerization is syndiotactic. In addition, no acetal signal was observed in

Figure 1a. Therefore, we concluded that the ROP of DMDO, accompanying with the elimination of acetaldehyde, occurred to yield a PCE. In order words, DMDO functioned as an alternative monomer to $\mathrm{M}_{\beta} \mathrm{BL}$. However, the molecular weights were lower than expected, probably due to the formation of cyclic oligomers by 'back-biting' transesterification reaction. The results of model experiment described in the next section supported the contribution of back-biting reaction.

\section{Copolymerization of DMDO}

The homopolymerization of DMDO did not result in polymers with high molecular weight. Generally speaking, the acylation reaction with secondary alcohol proceed slower than that with primary alcohol. Therefore, the secondary alcohol chain end would lead to slow propagating reaction. Then, $\varepsilon$ caprolactone (CL), a seven-membered lactone leading to primary alcohol chain end, was chosen as a comonomer (Scheme 2). The polymerization was conducted at $50{ }^{\circ} \mathrm{C}$ and $80{ }^{\circ} \mathrm{C}$ (Entries 6 and 7). In these experiments, the conversions of cis- and trans-isomers of DMDO were investigated, suggesting the cis-isomer was consumed faster than the trans-isomer; particularly, the conversion of trans-isomer at $50{ }^{\circ} \mathrm{C}$ was only $3 \%$ (Entry 6), indicating lower reactivity. Figure 1b shows the ${ }^{1} \mathrm{H}$ NMR spectrum of the obtained polymer in Entry 6. As no acetal signal was observed, ROP of DMDO accompanied the elimination of acetaldehyde similarly to homopolymerization. Although the signals split complex due to the random monomer sequences and uncontrolled stereoregularity, the signals around $5.6 \mathrm{ppm}$, which were not observed for homopolymer of DMDO, are assignable to the vinylidene signals for $\mathrm{M}_{2} \mathrm{M}_{1}$ sequence, while signals around $4.2 \mathrm{ppm}$ are assignable to $O$-methylene group of $\mathrm{M}_{2}$ in $\mathrm{M}_{1} \mathrm{M}_{2}$ sequence. In addition, characteristic signals of $O$-methylene group for $\mathrm{M}_{2} \mathrm{M}_{2}$ homosequence were observed at $4.1 \mathrm{ppm}$. The overall composition can be determined from the intensities of vinylidene signals of $\mathrm{M}_{1}$ unit and $O$-methylene signals of $\mathrm{M}_{2}$ unit. Hence, the monomer composition and content of each sequence were determined as follows: $\left[\mathrm{M}_{1}\right] /\left[\mathrm{M}_{2}\right]$ $=26 / 74$ and $\left[\mathrm{M}_{1} \mathrm{M}_{1}\right] /\left[\mathrm{M}_{1} \mathrm{M}_{2}\right] /\left[\mathrm{M}_{2} \mathrm{M}_{1}\right] /\left[\mathrm{M}_{2} \mathrm{M}_{2}\right]=20 / 6 / 14 / 60$, respectively. The existences of $\mathrm{M}_{1} \mathrm{M}_{2}$ and $\mathrm{M}_{2} \mathrm{M}_{1}$ sequences suggest the proceedings of copolymerization. The time vs. conversion plots are shown in Figure 2. CL was consumed faster than DMDO, and the relative reactivity of CL was estimated 2.4 times higher than DMDO from the ratio of conversions in early stage $(5 \mathrm{~min})$ at $80{ }^{\circ} \mathrm{C}$. The conversion of CL achieved 93\% after $6 \mathrm{~h}$, while 35\% of DMDO was consumed (Figure 2b). The conversions of DMDO increased to $70 \%$ after $24 \mathrm{~h}$, 
but $M_{\mathrm{n}}$ did not increase. On the other hand, Đs became larger from 1.56 to 2.32. Therefore, transesterification to yield cyclic oligomers would occur similarly to the homopolymerization of DMDO. In order to investigate the contribution of back-biting reaction, a homopolymer of $\mathrm{CL}\left(\mathrm{M}_{2}\right)$ was treated with DMDO $\left(\mathrm{M}_{1}\right)$ and DPP at $80{ }^{\circ} \mathrm{C}$ (See supporting information). After $24 \mathrm{~h}$, the $M_{\mathrm{n}}$ was decreased from 4700 to 1500 (Figure S5), while hetero-sequences such as $\mathrm{M}_{1} \mathrm{M}_{2}$ and $\mathrm{M}_{2} \mathrm{M}_{1}$ were observed in ${ }^{1} \mathrm{H}$ NMR spectrum (Figure S6). This implies transesterification would occur competitively to the propagation with DMDO.<smiles>C=C1C(=O)OC(C)OC1C</smiles>

DMDO<smiles>O=C1CCCCO1</smiles>

VL $(x=1)$

CL $(x=2)$

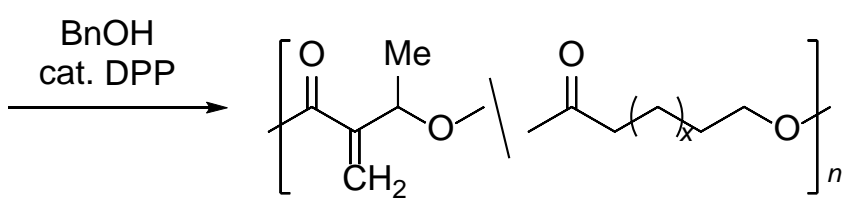

Scheme 2. Copolymerization of DMDO with VL and CL.

a

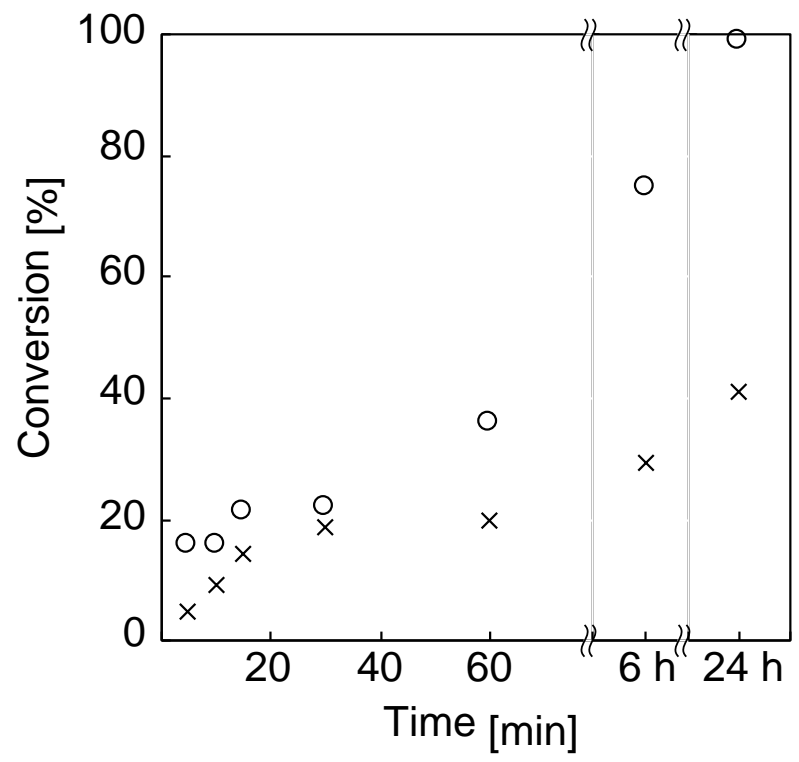

b

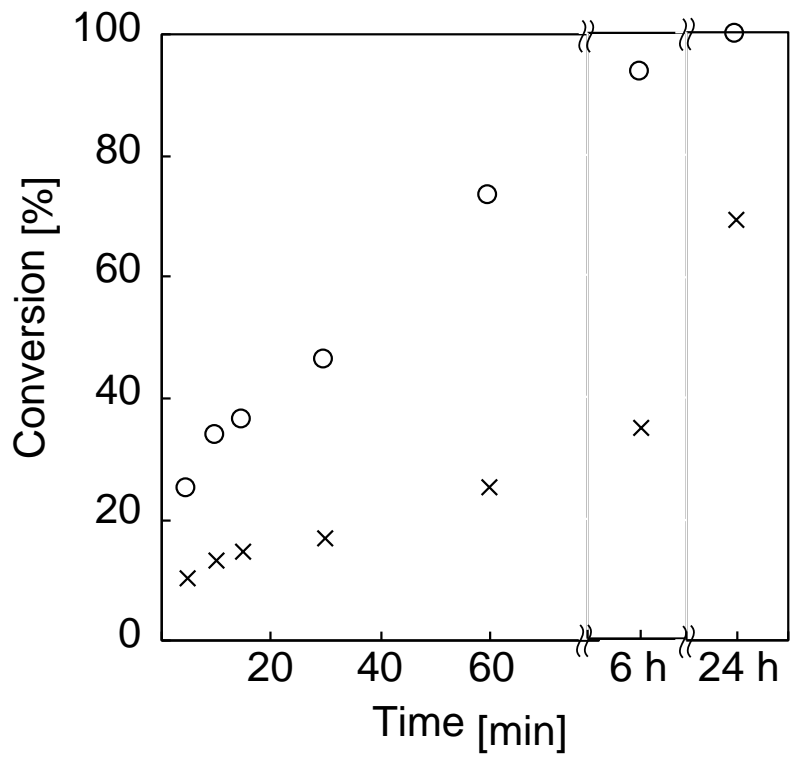

Figure 2. Time vs. conversion plots in the copolymerization of DMDO $(\times)$ and CL $(\circ)$ at $50{ }^{\circ} \mathrm{C}(\mathbf{a})$ and $80{ }^{\circ} \mathrm{C}(\mathbf{b})$.

The copolymerization with $\delta$-valerolactone (VL) was also investigated. Copolymerization at $50{ }^{\circ} \mathrm{C}$ and $80{ }^{\circ} \mathrm{C}$ (Entries 8 and 9) afforded the copolymers. Figure 1c shows the ${ }^{1} \mathrm{H}$ NMR spectrum of the obtained polymer in Entry 9. In a similar manner to the copolymerization with 
CL, the proceedings of copolymerization were confirmed.

\section{Polymerization of functionalized DMDO}

As well known, $\alpha$-exomethylene lactones have low reactivity in ROP, while the thiol adducts can polymerize smoothly even in homopolymerization[31,32]. Therefore, the ROP of thiol-functionalized DMDO, 5-[(benzylthio)methyl]-2,6-dimethyl-1,3-dioxa-4-one (BMDDO), was investigated. DMDO was treated with benzyl mercaptan in the presence of $\mathrm{Bu}_{3} \mathrm{P}$ for five days (Scheme 3). As BMDDO has three chiral centers, it potentially has eight $\left(=2^{3}\right)$ isomers. Among them, the four pair of isomers are in diastereotopic. In fact, four spots were found in thin layer chromatography (TLC), and the major product was isolated. The stereochemistry of isolated BMDDO was determined by NOESY spectrum (Figure S2) that all substituents located in cis-positions.<smiles>C=C1C(=O)OC(C)OC1C</smiles>

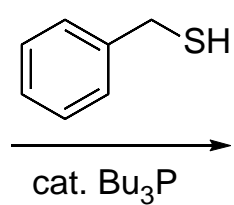

cat. $\mathrm{Bu}_{3} \mathrm{P}$<smiles>CC1OC(=O)C(CSCc2ccccc2)C(C)O1</smiles>

BMDDO

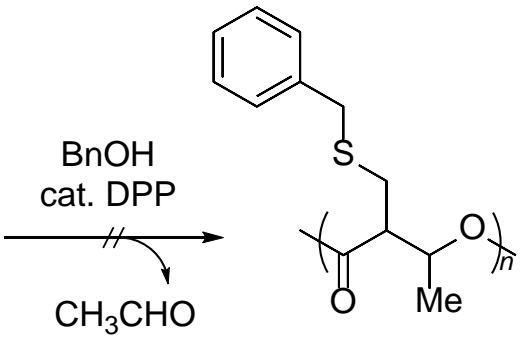

$\mathrm{CH}_{3} \mathrm{CHO}$

Scheme 3. Synthesis and polymerization of BMDDO.

Homopolymerizations of BMDDO in the presence of DPP at $25^{\circ} \mathrm{C}$ and $80{ }^{\circ} \mathrm{C}$ were attempted, but no polymeric product was obtained (Table S2, Entries 1 and 2). Then, copolymerization with VL at $25{ }^{\circ} \mathrm{C}$ was investigated (Entries 3 and 4). Although the polymer was obtained $\left(M_{\mathrm{n}}=3560, Ð=\right.$ 1.10), the content of BDDMO unit was low (11\%). Moreover, ${ }^{1} \mathrm{H}$ NMR signals implying the acetal exchange reaction was observed at $5.1 \mathrm{ppm}$ (Figure S3). Therefore, DPP is not suitable catalyst for ROP of BMDDO.

As Hillmyer and coworkers reported, [24], the ROP of cyclic hemiacetal ester undergo with acetal scission to afford a poly(hemiacetal ester). BMDDO, which formed an acetal with the alcohol chain end, obeyed this manner. On the other hand, DMDO favor acyl scission. The different polymerization behaviors between DMDO and BMDDO might be attributed to the existence of conjugation (Scheme 4). Both the acetal scission and acyl scission occur via protonation of carbonyl group. In general, 
acetal exchange occurs after the formation of oxonium cation (Scheme 4A, II for BDDMO). In case of DMDO, however, the protonated form is stable due to the weak resonance effect (Scheme $4 \mathrm{~B}, \mathrm{IV}$ and V) and the formation of oxonium cation VI is unfavored. On the other hand, the form V (enol) can accept the alcohol attack to form tetrahedral intermediate VII, leading to acyl scission. Hence, the unique reactivity of DMDO would be explained by the conjugated structure.

A
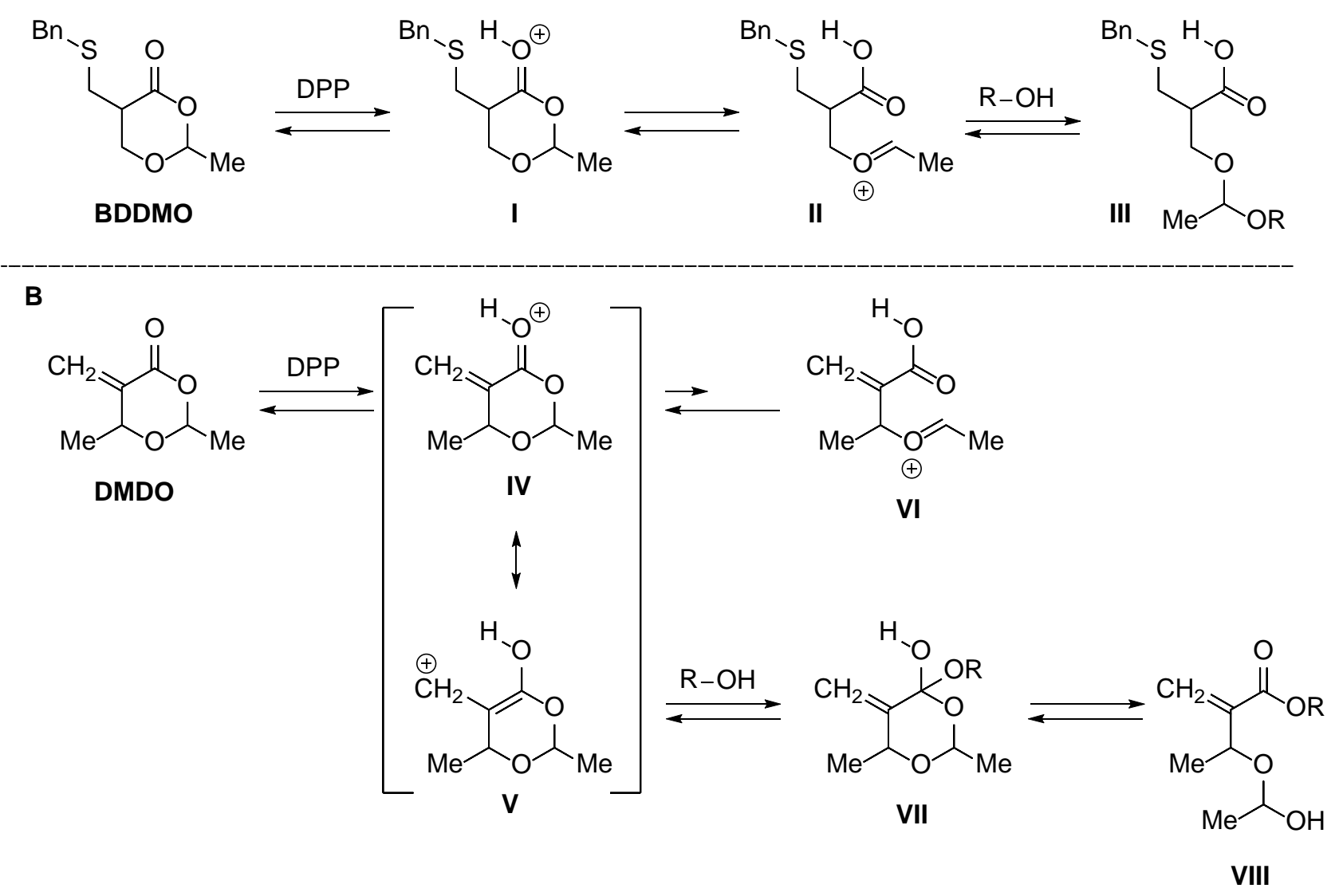

Scheme 4. Proposed mechanism of ROPs of BDDMO (A) and DMDO (B)

\section{Chemoselective Degradation at Conjugated Ester unit}

Recently, we have reported the main chain scission reaction of poly(conjugated ester)s that have oxycarbonyl group at the allylic position in the backbone[9]. The degradation was caused by conjugate substitution reaction, and thus chemoselective degradation at the acrylate skeletons could be achieved. In a similar way, the copolymer of DMDO and CL obtained in Entry 6 in Table 1 was treated with excess benzyl mercaptan (1.2 equimolar to the acrylate skeletons), an excellent nucleophile, in the presence of $\mathrm{Et}_{3} \mathrm{~N}$ (Scheme 5). Figure 3 shows the ${ }^{1} \mathrm{H}$ NMR spectra before and after the reaction. It is apparent that the vinylidene proton signals disappeared after the reaction, while signals A-D assignable to the conjugate substituted skeletons by COSY spectrum (Figure S4) were 
newly observed. Those changes suggest the main chain scission by conjugate substitution [9]. On the other hand, signals from CL units remained, indicating the degradation occurred chemoselectively. The decrease of molecular weight (Figure 4) also suggested the main chain scission reaction. Since overall SEC curves shifted, all polymer chains should possess the conjugated ester units as an internal unit for main chain scission, otherwise the some fragment of SEC peaks should remain the original position before the conjugate substitution reaction.

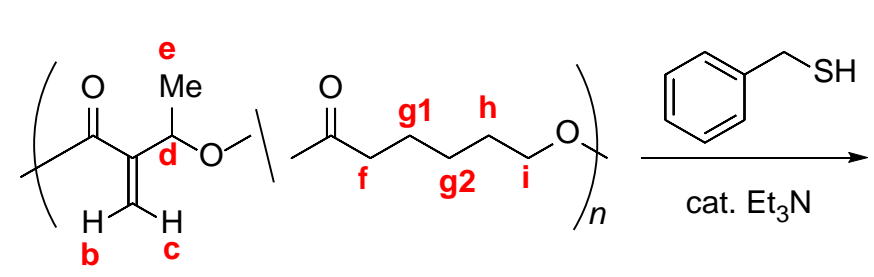<smiles>[B]C(C(=O)OC)=C(C)C(=O)OCc1ccccc1</smiles><smiles>COCCCCCC(=O)O</smiles>

Scheme 5. Chemoselective main chain scission by conjugate substitution.

\section{before}

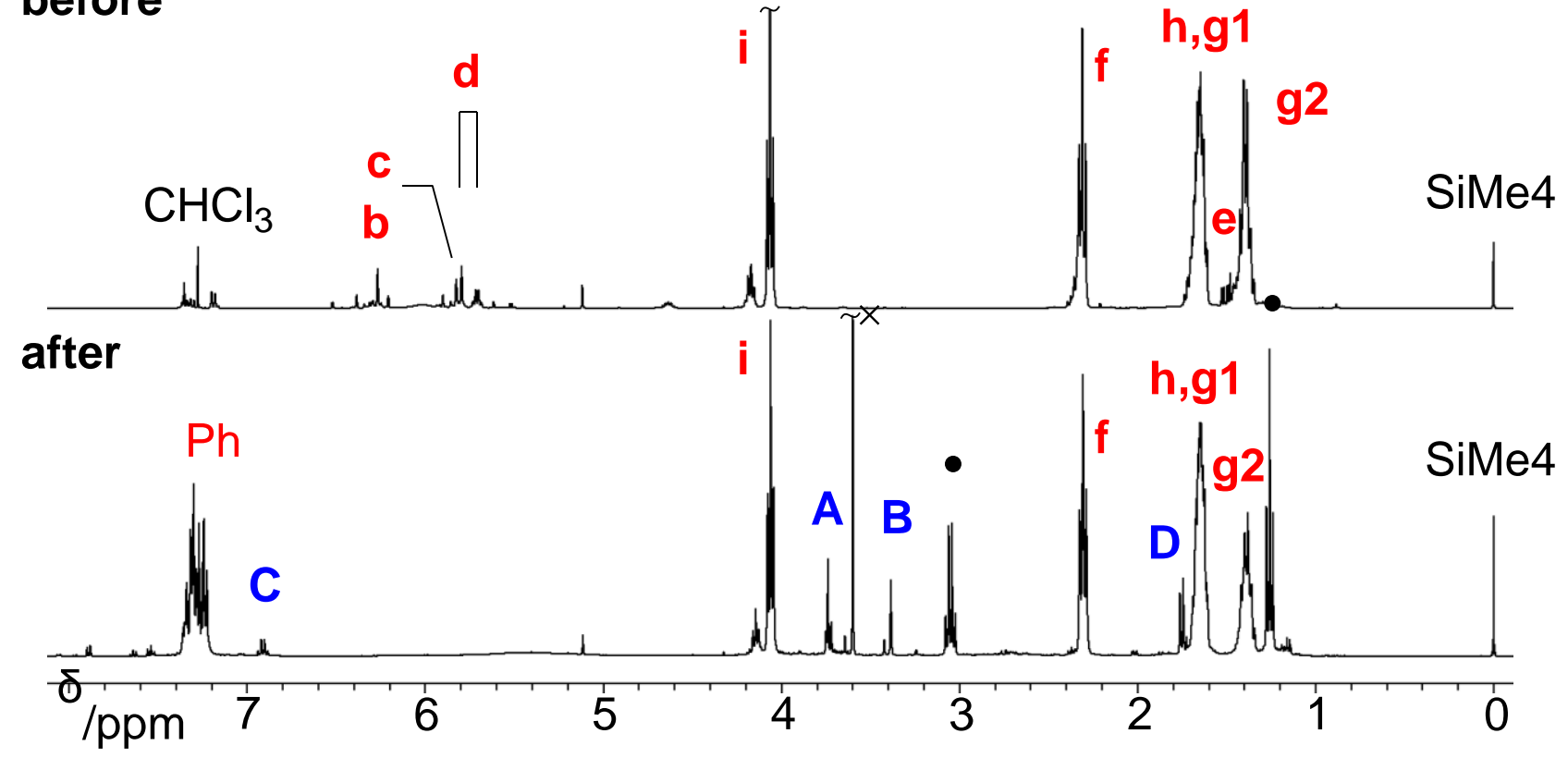

Figure 3. ${ }^{1} \mathrm{H}$ NMR spectra before and after the degradation of the copolymer of DMDO and CL. Labels correspond to those in Figure 1 and Scheme 5. •: Et ${ }_{3} \mathrm{~N}, \times$ : Benzyl mercaptan. 


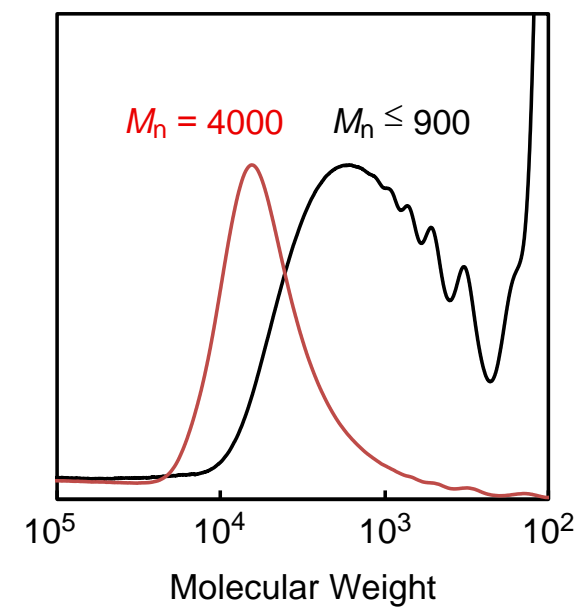

Figure 4. Change of molecular weight before and after degradation of the copolymer of DMDO and CL.

\section{Conclusion}

ROP of DMDO proceeded accompanying with the elimination of acetaldehyde to afford a PCE with a similar structure to poly $\left(\mathrm{M}_{\beta} \mathrm{BL}\right)$. Although the homopolymerization and copolymerization with VL and CL were not living and thus the resulting molecular weights did not obey the theoretical values, DMDO exhibited a potential as an alternative monomer to $M_{\beta} B L$. As the preparation of $M_{\beta} B L$ is not easier than that of DMDO, the current strategy remains promising. Further researches to develop effective catalyst for DMDO, including organometallic complexes, are expected to overcome the low reactivity. From a viewpoint of degradable polymer, the conjugated ester skeletons allowed chemoselective main chain scission at the ester substituent. Since the reaction proceeded under a mild condition, the incorporation of conjugated ester skeletons would be effective to assist the biodegradation of aliphatic polyesters. For this purpose, not only DMDO but also $\mathrm{M}_{\beta} \mathrm{BL}[15]$ and other similar $\alpha$-exomethylene lactones seems useful.

\section{Acknowledgement}

The donation of acryloyl chloride from the Iharanikkei Chemical Industry Co., Ltd is gratefully acknowledged. This research was financially supported by the JSPS KAKENHI grant (no. 16K05792 and 19H02763), Tokuyama Science Foundation (for Y. K.) and Ube Industries Research Foundation: The UBE Foundation (for Y. K.). 


\section{References}

[1] J. Zhou, A.M. Schmidt, H. Ritter, Macromolecules 43 (2006) 2804-2807

[2] S. Ji, B. Bruchmann, H.-A. Klok, Macromolecules 44 (2011) 5218-5226

[3] C. Peng, A. Joy, Macromolecules 47 (2014), 1258-1268.

[4] S. Chanda, S. Ramakrishnan, Polym. Chem. 6 (2015) 2108-2114

[5] M. Winkler, T. M. Lacerda, F. Mack, M.A.R. Meier, Macromolecules 48 (2015) 1398-1403

[6] T. Robert, S. Friebel, Green Chem. 18 (2016) 2922-2934

[7] M. Singh, R. Rathi, A. Singh, J. Heller, G.P.Talwar, J. Kopecek, Int. J. Pharm 76 (1991) R5-R8

[8] D.G. Barrett, T.J. Merkel, J.C. Luft, M.N. Yousaf, Macromolecules 43 (2010) 9660-9667

[9] Y. Kohsaka, T. Miyazaki, K. Hagiwara, Polym. Chem. 9 (2018) 1610-1617.

[10]S. Habaue, M. Asai, M, Morita, Y. Okamoto, H. Uyama, S. Kobayashi, Polymer 44 (2003) 51955200

[11]H. Uyama, S. Kobayashi, M. Morita, S. Habaue, Y. Okamoto, Macromolecules 34 (2001) 65546556

[12]M. Hong, E.Y.-X. Chen, Macromolecules 47 (2014) 3614-3624

[13]X. Tang, M. Hong, L. Falivene, L. Caporaso, L. Cavallo, E.Y.-X. Chen, J. Am. Chem. Soc. 128 (2016) 14326-14337

[14]Y.-C. Xu, H. Zhou, X.-Y. Sun, W.-M. Ren, X.-B. Lu, Macromolecules 49 (2016) 5782-5787

[15]Y.-C. Xu, W.-M. Ren, H. Zhou, G.-G Gu, X.-B. Lu, Macromolecules 50 (2017) 3131-3142

[16]Y. Tachibana, T. Baba, K. Kasuya, Polym Degrad. Stabil. 137 (2017) 67-74

[17]Y. Kohsaka, Y. Matsumoto, T. Zhang, Y. Matsuhashi, T. Kitayama, J. Polym. Sci. Part A: Polym. Chem. 54 (2016) 955-961

[18]Y. Kohsaka, Y. Matsumoto, T. Kitayama, Polym. Chem. 6 (2015) 5026-5029

[19]Y. Kohsaka, K. Hagiwara, K. Ito, Polym. Chem. 8 (2017) 976-979

[20]S. Habaue, M. Morita, Y. Okamoto, Macromolecules 35 (2002) 2432-2434 
[21]S. Habaue, M. Morita, Y. Okamoto, Polymer 43 (2002) 3469-3474

[22]Y. Kohsaka, K. Yamamoto, K. Suzawa, T. Kitayama, Polym. Bull. 74 (2017) 1934-1948

[23]A.E. Neitzel, M.A. Petersen, E. Kokkoli, M.A. Hillmyer, ACS Macro Lett. 3 (2014) 1156-1160

[24]A. E. Neitzel, T. J. Haversang, M. A. Hillmyer, Ind. Eng. Chem. Res. 55 (2016) 11747-11755

[25]Y. Xu, M. R. Perry, S. A. Cairnsb, M. P. Shaver, Polym. Chem. 10 (2019) 3048-3054

[26]S. A. Cairns, A. Schultheiss, M. P. Shaver, Polym. Chem. 8 (2017) 2990-2996

[27]S. Kaihara, S. Matsumura, A.G. Mikos, J.P. Fischer, Nature Protocols 2 (2007) 2727-2771.

[28]R.C. Pratt, B.G.G. Lohmeijer, D.A. Long, R.M. Waymouth, J.L. Hedrick, J. Am. Chem. Soc. 128 (2006) 4556-4557

[29]B.G.G. Lohmeijer, R.C. Pratt, F. Leibfarth, J.W.Logan, D.A. Long, A.P. Dove, F. Nederberg, J. Choi, C. Wade, R.M. Waymouth, J.L. Hedrick, Macromolecules 39 (2006) 8574-8583

[30]T. Isono, I. Otsuka, D. Suemasa, C. Rochas, T. Satoh, R. Borsali, T. Kakuchi, Macromolecules 46 (2013) 8932-8940

[31]T. Fuoco, A. Finne-Wistrand, D. Pappalardo, Biomacromolecules 17 (2016) 1383-1394

[32]X. Li, H. Li, Y. Zhao, X. Tang, S. Ma, B. Gong, M. Li, Polym. Chem. 6 (2015) 6452-6456 